\title{
Quantities of Arsenic-Treated Wood in Demolition Debris Generated by Hurricane Katrina
}

\author{
Brajesh Dubey $^{\dagger}$, Helena M. Solo-Gabriele ${ }^{\star}, \ddagger$, and Timothy G. Townsend ${ }^{\dagger}$ \\ $\dagger$ Department of Environmental Engineering Sciences, University of Florida, PO Box 116450, Gainesville, \\ Florida 32611-6450 \\ $\$$ Department of Civil, Architectural and Environmental Engineering, University of Miami, Coral Gables, \\ Florida 33124-0630
}

\section{Abstract}

The disaster debris from Hurricane Katrina is one of the largest in terms of volume and economic loss in American history. One of the major components of the demolition debris is wood waste of which a significant proportion is treated with preservatives, including preservatives containing arsenic. As a result of the large scale destruction of treated wood structures such as electrical poles, fences, decks, and homes a considerable amount of treated wood and consequently arsenic will be disposed as disaster debris. In this study an effort was made to estimate the quantity of arsenic disposed through demolition debris generated in the Louisiana and Mississippi area through Hurricane Katrina. Of the 72 million cubic meters of disaster debris generated, roughly 12 million cubic meters were in the form of construction and demolition wood resulting in an estimated 1740 metric tons of arsenic disposed. Management of disaster debris should consider the relatively large quantities of arsenic associated with pressure-treated wood.

\section{Introduction}

The total disaster debris produced from Hurricane Katrina in the two hardest hit states, Mississippi and Louisiana, was estimated at 72 million cubic meters $(1,2)$. Disaster debris is composed primarily of construction and demolition (C\&D) debris (50\%) and vegetative wood waste (30\%) (3). C\&D debris consists of materials used in construction including concrete, roofing materials, drywall, and wood. Vegetative wood waste consists primarily of shrubs, tree branches, and tree trunks. Because of its nature, vegetative waste does not contain wood preservatives. However, wood used for construction is frequently treated to protect the wood from fungi and termite attack. The most common wood treatment preservative manufactured in the United States through 2003 is chromated copper arsenate (CCA) (4). Since 2003, nonarsenical copper-based wood preservatives, such as alkaline copper quat (ACQ) and copper boron azole (CBA), have been primarily used for the residential market. The typical concentrations of arsenic, chromium, and copper in CCA-treated wood used for residential applications are $1800-2800 \mathrm{mg} / \mathrm{kg}, 1900-3100 \mathrm{mg} / \mathrm{kg}$, and $1200-1800 \mathrm{mg} / \mathrm{kg}$, respectively (5). Typical concentrations of copper in ACQ and CBA treated wood are $3500-4500 \mathrm{mg} / \mathrm{kg}$ and $2500-3500 \mathrm{mg} / \mathrm{kg}$, respectively (5). As a result of these high levels of metals, the C\&D portion of disaster debris can be potentially contaminated with metals. Among the metals

\footnotetext{
* Corresponding author phone: +1-305-284-2908; fax: +1-305-284-3492; e-mail: hmsolo@ miami.edu.

Supporting Information Available=: Calculation details and debris photographs. This material is available free of charge via the Internet at http://pubs.acs.org.
} 
contained in wood preservatives, arsenic is of primary concern because of its high human toxicity (6).

CCA-treated wood has been commonly observed in C\&D waste, as documented through studies conducted in Florida (7-9). Within the wood waste component of C\&D, the fraction of CCA-treated wood has been observed to vary from 8 to $22 \%$. Research evaluating technologies for separating treated wood (particularly CCA) from other wood products has been conducted in an effort to remove arsenic contamination due to inadvertent inclusion of CCA-treated wood within mixed C\&D debris at recycling facilities. Technologies available for rapid identification and quantification include near-infrared (NIR) spectroscopy, laserinduced breakdown spectroscopy (LIBS), and X-ray fluorescence spectroscopy (XRF) $(8,10$, 11). Recently, handheld XRF units have been used for research to document their utility to further augment sorting and quantification of metals within treated wood (9). Such technology, because of portability and provision of rapid results, is ideal for evaluating the potential contamination of disaster debris with wood based preservatives.

The objectives of the present study were to evaluate wood waste generated by hurricane debris for the presence of arsenical-based preservatives (i.e., CCA) and to use these results to estimate the potential extent of arsenic associated with disaster debris. Handheld XRF units were used for this evaluation. Results from the study are useful for establishing policy concerning the management of wood waste after major disasters.

\section{Methods and Materials}

\section{Site Selection for Study}

Measurements were taken during March 2006 within disaster debris from the New Orleans area. The wood waste portion of the disaster debris was evaluated at seven different sites (Figure 1). Sites included areas with extreme damage characterized by complete collapses of homes and areas where the damage was primarily due to flooding. Among the area with major damage, four sites were selected: two each at Upper Ninth Ward (Sites W1 and W2) and Lower Ninth Ward (Sites W3 and W4). The other three sites (Sites W5 through W7) were located in the inner area of the city where damage was mostly due to flooding.

\section{Measurement of Chemical Treatment within Wood Waste}

A total of 225 dimensional lumbers were evaluated using an XRF-analyzer (Innov-X model $\alpha-2000 S$ ) with at least 24 dimensional lumbers evaluated at each site. The number of lumbers included in the study from a particular site was based upon the apparent volume of wood pile at that particular location, with larger piles resulting in a greater number of analyses. The selection of dimensional lumber for analysis was conducted in a uniform manner with wood pieces tested from different parts of the wood waste pile. Conversion of the XRF readings to As concentrations was based upon a calibration curve between the XRF results and As measurements using traditional atomic absorption analysis for the particular instrument used in this study (12; see Supporting Information for more details.)

\section{Calculation of Amount of Arsenic Associated with Treated Wood Waste}

The quantity of arsenic associated with demolition debris was computed as the product of the total amount of wood waste (33\% of demolition debris (3)), the fraction of wood samples that tested positive for arsenic treatment, and the geometric mean arsenic concentration. The geometric mean of the arsenic concentration was used because the data were found to be lognormal distributed (see Figure 3). 


\section{Results and Discussion}

\section{Statistics of Treated Wood Sample from Each Site}

Overall, 52 dimensional lumbers were determined to have been treated with an arsenical preservative among the 225 samples evaluated at the seven sites (Table 1) or roughly $23 \%$ on a piece-by-piece basis. For individual sites the fraction that was treated with CCA varied from $4 \%$ for Site 6 to $36 \%$ for Site 2. This observation correlated with previous research conducted in Florida (8-22\% CCA in C\&D waste; 7-9). The As concentration in the samples testing positive for arsenic ranged from 75 to $4900 \mathrm{mg} / \mathrm{kg}$. The large range of variation of the As concentration from different treated wood lumber could be attributed to several factors including the initial degree of treatment for that particular piece, impregnation, fixation procedure, the extent of weathering, and the natural properties of the wood which impact chemical retention. Furthermore, the average concentration from each site was variable (Figure 2) ranging from $248 \mathrm{mg} / \mathrm{kg}$ for Site 6 to $2690 \mathrm{mg} / \mathrm{kg}$ for Site 4 . Of note was that a significant proportion of the wood evaluated contained non-arsenical copper-based preservatives (10.2\%) and this was noted in the waste piles characterized by newer construction.

\section{Amount of Arsenic in Disaster Debris}

The frequency distribution of As concentrations from the sample set was found to be lognormally distributed (Figure 3). The geometric mean of the arsenic concentration in the treated wood samples was found to be $1240 \mathrm{mg} / \mathrm{kg}$. With $50 \%$ of the disaster debris as construction and demolition waste of which $33 \%$ is wood waste and $23 \%$ of the wood waste being CCAtreated wood as per the field data, the total amount of As disposed in the environment in the form of disaster debris in the two states of Louisiana and Mississippi is estimated to be 1740 metric tons. In order to better visualize the magnitude, this quantity was scaled against soil and water relative to the surface area of the Mississippi and Louisiana states and the volume of water of Lake Pontchartrain, respectively. Using these scaling computations, the 1740 metric tons of arsenic was computed to be capable of increasing the concentration of a soil volume equivalent to the upper $1 \mathrm{in}$. of these two states' land by almost $0.17 \mathrm{mg} / \mathrm{kg}$; it is capable of increasing the concentration of a volume of water equivalent to Lake Pontchartrain by 280 $\mu \mathrm{g} / \mathrm{L}$ (28 times the drinking water limit of $10 \mu \mathrm{g} / \mathrm{L}$ ).

\section{Implication for Wood Waste Management after Disaster}

Construction and demolition waste from the Hurricane Katrina disaster is currently being disposed in unlined C\&D landfills. This disposal practice should be re-evaluated with respect to the potential for leaching of arsenic from pressure-treated wood (13-16) and in light of studies which suggest that such leaching can potentially impact groundwater quality (17-18). The need to consider the potential for arsenic leaching from disposed treated wood is further emphasized by the recent reduction of the drinking water limit from $50 \mu \mathrm{g} / \mathrm{L}$ to $10 \mu \mathrm{g} / \mathrm{L}$ (19). Although the focus of the current study was on quantifying arsenic, of note is that copper and chromium contained in pressure-treated wood can also be of concern due to the toxicity of copper to aquatic organisms (20-22) and the potential for chromium conversion to a more toxic form as $\mathrm{Cr}$ (VI) under certain environmental conditions (23). Future studies should focus on quantifying the $\mathrm{Cr}$ and $\mathrm{Cu}$ contributions in addition to As.

Given the large quantities of treated wood disposed during natural disasters, such as in the aftermath of Hurricane Katrina, disaster debris management plans should encourage communities to segregate treated wood for better management of wood waste as a whole. Although measuring every piece of wood is not practical in large scale disasters such as those which occurred in 2005 in the New Orleans area and Gulf Coast Region, those responsible for disaster debris management should consider the potential for arsenic contamination from treated wood as they make decisions concerning ultimate disposal. 


\section{Supplemental Materials}

Refer to Web version on PubMed Central for supplementary material.

\section{Acknowledgements}

Funding for this work was provided through the Hinkley Center for Solid and Hazardous Waste Management and by the NSF-SGER Program (OCE 0554402) and by the NSF-NIEHS Oceans and Human Health Program (NSF OCE-0432368 and NIEHS P50 ES12736). We gratefully thank Timothy Dixon and Dean Whitman for provision of the basemap for Figure 1 and Joe Mathews for preparing this figure.

\section{Literature Cited}

1. Mississippi Department of Environmental Quality (MDEQ). [August 2006]. website. http://deq.state.ms.us/Mdeq.nsf/page/Main_Home?OpenDocument;accessed during

2. Louisiana Department of Environmental Quality (LDEQ). [August 2006]. website. http://www.deq.louisiana.gov/portal/;accessed during

3. Reinhart D, McCreanor P. Disaster debris management - planning tools. September;1999 Final Report submitted to U.S. Environmental Protection Agency Region IV

4. Solo-Gabriele H, Townsend T. Disposal practices and management alternatives for CCA-treated wood waste. Waste Manage Res 1999;17:378-389.

5. AWPA. American Wood Preservers' Association Book of Standards. American Wood-Preservers' Association; Selma, AL: 2003.

6. Shibata, T. Dislodgeable arsenic from in-service CCA-treated wood. In: Townsend, T.; Solo-Gabriele, H., editors. Environmental Impacts of Treated Wood. CRC Press; Boca Raton, FL: 2006. p. 237-256.

7. Tolaymat T, Townsend T, Solo-Gabriele H. Chromated copper arsenate treated wood in recovered wood. Environ Eng Sci 2000;7(1):19-28.

8. Solo-Gabriele H, Townsend T, Hahn D, Moskal T, Hosein N, Jambeck J, Jacobi G. Evaluation of XRF and LIBS technologies for on-line sorting of CCA-treated wood waste. Waste Manage 2004;24:413424.

9. Jacobi G, Solo-Gabriele H, Townsend T, Dubey B. Evaluation of Methods for Sorting CCA-treated Wood. Waste Manage. 10.1016/j.wasman.2006.09.014in press

10. Homan, W.; Miltz, H. Evaluation of Rapid Methods for Detecting Wood Preservatives in Waste Wood. International Research Group on Wood Preservation; Stockholm, Sweden: 1994. IRG/WP 94-50024

11. Peylo, A.; Peek, R. Rapid Analytical Methods for Wood Waste-An Overview. International Research Group on Wood Preservation; Stockholm, Sweden: 1998. IRG/WP 98-50104

12. Block C, Shibata T, Solo-Gabriele H, Townsend T. Use of Handheld X-ray Fluorescence Spectrometry Units for Identification of Arsenic in Treated Wood. Environ Pollut. 10.1016/j.envpol. 2006.11.013in press

13. Jambeck J, Townsend T, Solo-Gabriele H. Leaching of chromated copper arsenate (CCA)-treated wood in a simulated monofill and its potential impacts to landfill leachate. J Hazard Mater 2006;A135:21-31. [PubMed: 16406290]

14. Townsend T, Dubey B, Tolaymat T, Solo-Gabriele H. Preservative leaching from weathered CCAtreated wood. J Environ Manage 2005;75(2):105-113. [PubMed: 15763153]

15. Townsend T, Tolaymat T, Solo-Gabriele H, Dubey B, Stook K, Wadanambi L. Leaching of CCA treated wood: implications for waste disposal. J Hazard Mater 2004;B114:75-91. [PubMed: 15511577]

16. Dubey, B.; Townsend, T.; Solo-Gabriele, H. Metal leaching from pressure treated wood in sanitary landfill leachate. In Proceedings 2004; IRG/WP 04-50220; Stockholm, Sweden: 2004.

17. Dubey, B. PhD Dissertation. University of Florida; Gainesville, FL: 2005. Comparison of environmental impacts of wood treated with chromated copper arsenate (CCA) and three As-free preservatives. 
18. Jambeck, J. PhD Dissertation. University of Florida; Gainesville, FL: 2004. The disposal of CCAtreated wood in simulated landfills: potential impacts.

19. National primary drinking water regulations; arsenic and clarifications to compliance and new source contaminants monitoring. Fed Regist 2001;66(194):50961-50963.

20. Weis P, Weis J. Accumulation of metals in consumers associated with chromated copper arsenatetreated wood panels. Mar Environ Res 1999;48:73-81.

21. Stook K, Tolaymat T, Ward M, Dubey B, Townsend T, Solo-Gabriele H, Bitton G. Relative Leaching and Aquatic Toxicity of Pressure-Treated Wood Products Using Batch Leaching Tests. Environ Sci Technol 2005;39:155-163. [PubMed: 15667090]

22. Stook K, Dubey B, Ward M, Townsend T, Bitton G, Solo-Gabriele H. An Evaluation of the Heavy Metal Toxicity of Pressure Treated Wood Leachates with MetPLATE. Bull Environ Contam Toxicol 2004;73(6):987-994. [PubMed: 15674711]

23. Song J, Dubey B, Jang Y, Townsend T, Solo-Gabriele H. Implication of Chromium Speciation on Disposal of Discarded CCA-Treated Wood. J Hazard Mater 2006;B128:280-288. [PubMed: 16165268] 


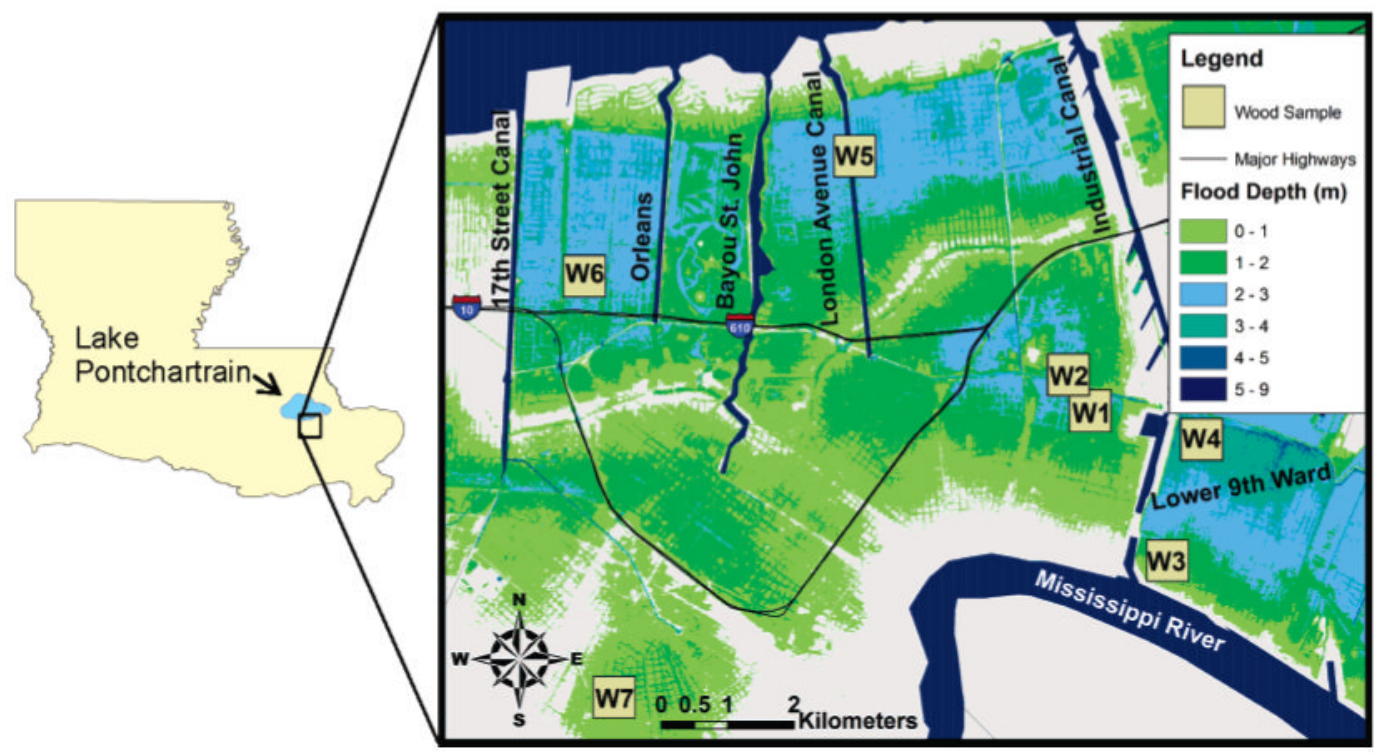

Figure 1.

Sampling locations W1 through W7 where treated wood samples were evaluated using the XRF unit. The image was developed using the GPS coordinate recorded during the sampling event. Background image showing inundation depths was provided by Dean Whitman of Florida International University and Tim Dixon of the University of Miami. 


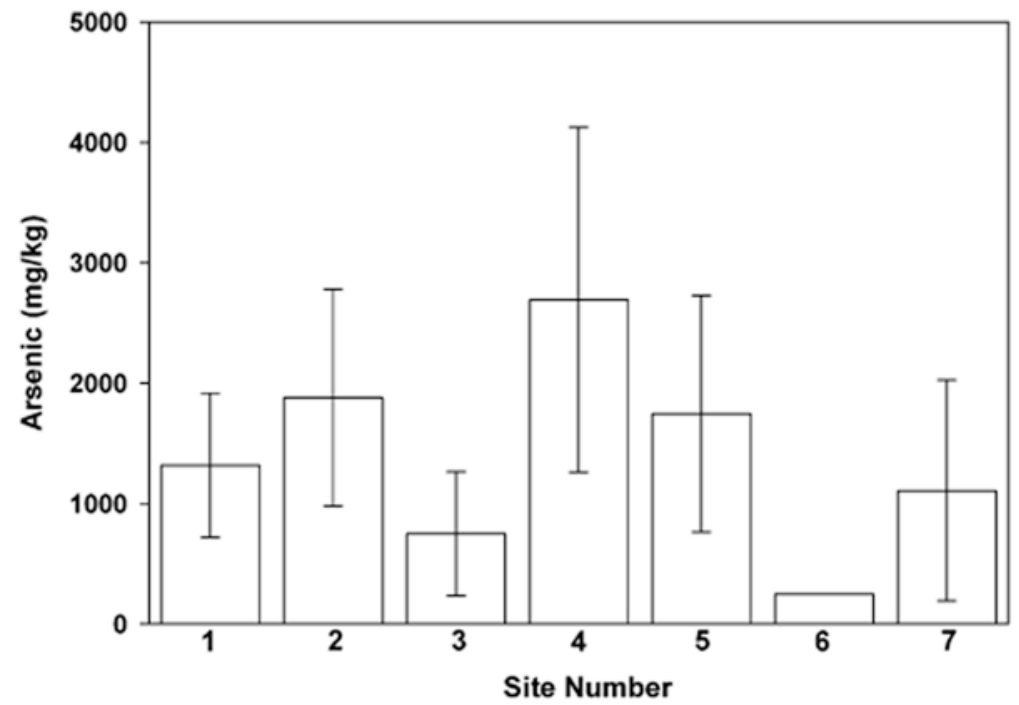

Figure 2.

Average arsenic concentrations from the samples tested as CCA at seven sites (The error bar represents the standard deviation for the sample set for that particular site. For site-6, only one sample tested positive for CCA, hence no error bar is shown for this site). 


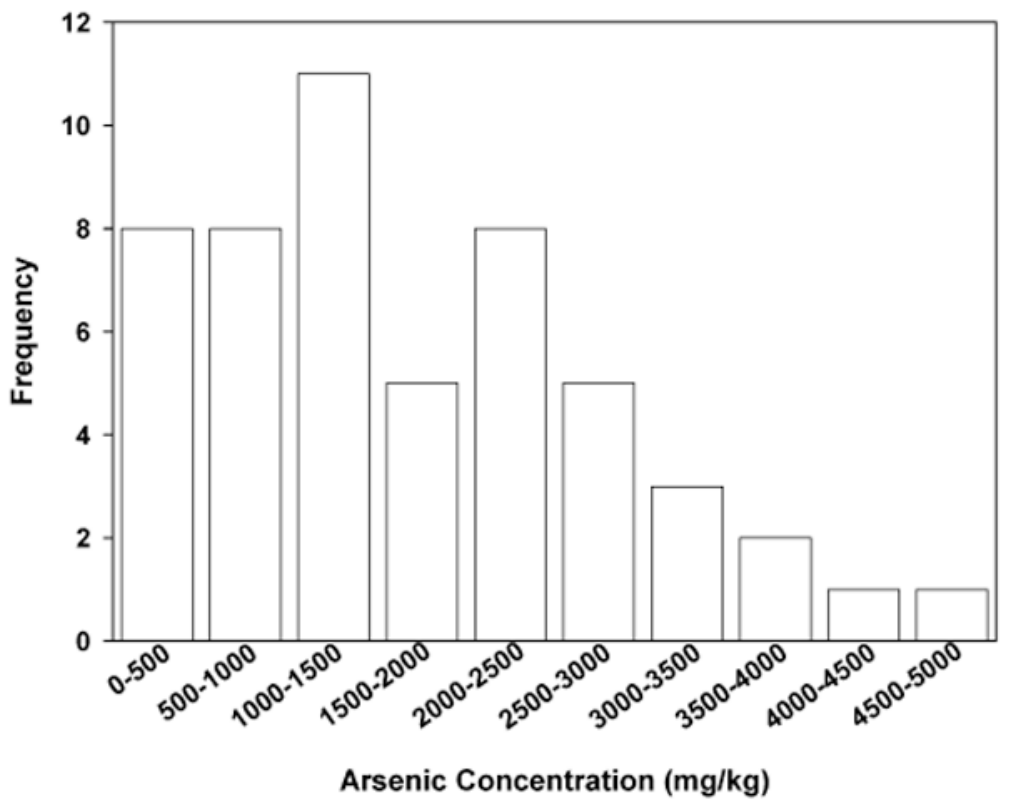

Figure 3.

Frequency plot for arsenic concentration ranges in lumbers testing positive for arsenic treatment at the seven sites evaluated. 


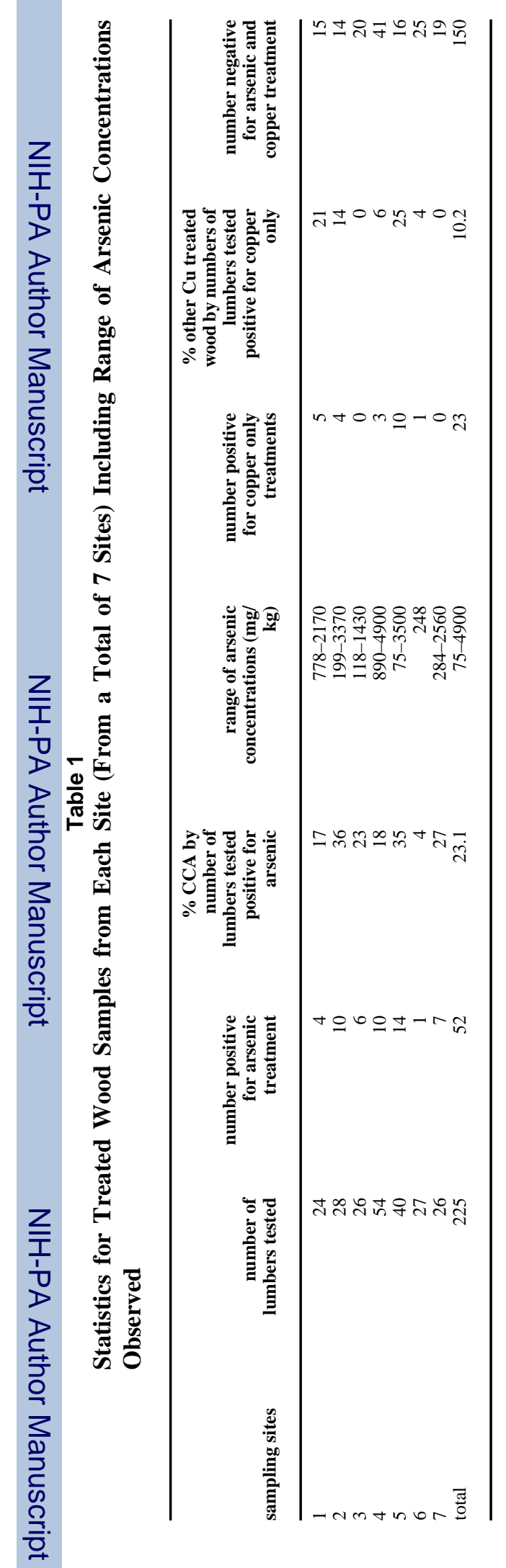

Environ Sci Technol. Author manuscript; available in PMC 2008 October 15. 